\title{
An application of TOPSIS method for ranking different strategic planning methodology
}

\author{
Mohsen Esfandiari ${ }^{\mathrm{a}}$ and Mehdi Rizvandi ${ }^{\mathrm{b} *}$
}

${ }^{a}$ Department of Industrial Engineering, Qazvin Branch, Islamic Azad University, Qazvin, Iran

${ }^{b}$ Department of Management, East Azarbaijan Science and Research Branch, Islamic Azad University, Tabriz, Iran

\section{H R O N I C L E A B S TRACT}

Article history:

Received January 14, 2014

Accepted 10 June 2014

Available online

June 122014

Keywords:

Strategic planning

TOPSIS

Information technology

\section{Introduction}

Strategy planning plays essential role on development of business organizations. It is important to use reliable long-term plans to reach organizational objectives. There are literally various strategies where people could simply switch from one to another one. Making strategy selection is normally a multi criteria decision-making problem since there are more than one single criteria involved in making appropriate decisions.

For over thirty years, there have been tremendous efforts on having efficient techniques proposed to rank various alternatives analytical hierarchy process (AHP) (Saaty, 1992), Entropy and Technique for Order Preference by Similarity to Ideal Solution (TOPSIS). Some of the techniques ask decision maker (DM) to express his/her insights to rank preferences, for example AHP and some others do not. When we want to prevent direct communication with DM, we normally look for other techniques 
for ranking various alternatives and there are growing interests to use methods for decision-making processes.

\section{The proposed study}

This paper presents an empirical investigation to rank different business development strategies for information technology improvement. The study considers five different strategies including Critical Success Factors Analysis, Business Systems Planning, Porter's forces model, SWOT analysis, Value chain Analysis and MIN and rank them based on TOPSIS technique. We first briefly explain TOPSIS technique. The study has accomplished in one of municipality organizations in city of Tehran, Iran. The study has gathered the necessary information from experts. In our survey, over two third of the participants had more than three years of job experiences and all participants maintained some university education in difference engineering as well as computer science.

\subsection{TOPSIS technique}

TOPSIS, originally introduced by Hwang and Yoon in 1981, is a sophisticated ranking technique implemented in various information technology applications of science and engineering (Chang et al., 2010). Traditional TOPSIS method chooses alternatives, which concurrently have the shortest distance from the positive ideal solutions and the longest distance from the negative-ideal solutions. TOPSIS makes full implementation of attribute data, provides a cardinal ranking of alternatives, and does not request attribute preferences to be independent. To apply this technique, attribute values must be numeric, monotonically non-increasing or non-decreasing, and have commensurable units (Chen and Hwang, 1992; Yoon \& Hwang, 1995).

There are literally various applications of TOPSIS adopted in various areas of scientific societies. There are various extensions of TOPSIS such as fuzzy TOPSIS (Aiello et al., 2009). Amiri (2010), for example, attemped project selection for oil-fields development by implementing the combined analytical hierachy process (AHP) and fuzzy TOPSIS methods. Athanasopoulos et al. (2009) developed a decision support system for coating selection based on fuzzy logic and multi-criteria decision making. Awasthi et al. (2011a) used an application of fuzzy TOPSIS for assessing sustainable transportation systems. Awasthi et al. (2011b) proposed a hybrid approach based on SERVQUAL and fuzzy TOPSIS to evaluate transportation service quality. Performance measurement is another TOPSIS application and its extentions such as fuzzy TOPSIS. Krohling and Campanharo (2011) applied fuzzy TOPSIS for group decision making for a case study of accidents with oil spill in the sea. Thomaidis et al. (2008) used TOPSIS for the wholesale natural gas market prospects in the energy community treaty countries.

Aydogan (2011) consided a study for performance measurement model in Turkey by looking into Turkish aviation companies using the rough-AHP and TOPSIS methods under fuzzy environment. Chamodrakas et al. (2009) investigated customer evaluation for order acceptance using a novel class of fuzzy methods based on TOPSIS. Kelemenis et al. (2011) studied on support managers' selection using an extension of fuzzy TOPSIS.

TOPSIS has been also used in internet services, for instance, Cheng et al. (2011) applied TOPSIS for Web service selection problems. Sun and Lin (2009) used fuzzy TOPSIS method for evaluating the competitive advantages of shopping websites. Yu et al. (2011) executed ranking of e-commerce websites in an e-alliance using Fuzzy TOPSIS.

\subsection{The method}

Let $x_{i j}$ be the inputs for matrix of priorities where there are $i=1, \cdots, m$ alternatives and $j=1, \cdots, n$ criteria. There are six steps associated with the implementation of TOPSIS as follows, 
Step 1. Construct normalized decision matrix

$$
r_{i j}=\frac{x_{i j}}{\sqrt{\sum_{i=1}^{m} \sum_{j=1}^{n} x_{i j}^{2}}}
$$

Step 2. Construct the weight normalized matrix

$$
v_{i j}=w_{i} r_{i j}, i=1, \cdots, m \quad j=1, \cdots, n
$$

Step 3. Determin the positive and negative ideal solutions

$$
\begin{aligned}
& A^{+}=\left\{v_{1}^{+}, \cdots, v_{n}^{+}\right\}, \text {where } v_{j}^{+}=\left\{\max \left(v_{i j}\right) \text { if } j \in J ; \min \left(v_{i j}\right) \text { if } j \in J^{\prime}\right\} \\
& A^{-}=\left\{v_{1}^{-}, \cdots, v_{n}^{-}\right\}, \text {where } v_{j}^{*}=\left\{\min \left(v_{i j}\right) \text { if } j \in J ; \max \left(v_{i j}\right) \text { if } j \in J^{\prime}\right\}
\end{aligned}
$$

Step 4. Calculate seperation (positive and negative) measures for each alternative

$$
S_{i}^{+}=\sqrt{\sum_{\mathrm{j}=1}^{\mathrm{n}}\left(v_{j}^{+}-v_{i j}\right)^{2}}, S_{i}^{-}=\sqrt{\sum_{\mathrm{j}=1}^{\mathrm{n}}\left(v_{j}^{-}-v_{i j}\right)^{2}}, i=1, \cdots, m
$$

Step 5. Calculate the relative closness to the ideal solution

$$
C_{i}^{+}=\frac{S_{i}^{-}}{S_{i}^{-}+S_{i}^{+}}, 0<C_{i}^{+}<1, i=1, \cdots, m
$$

The proposed study of this paper considers different criteria for ranking various alternatives, which are summarized in Table 1 as follows,

\section{Table 1}

The summary of criteria for ranking different stratgic planning

\begin{tabular}{llll}
\hline Item & Description & Item & Description \\
\hline 1 & Type of organization & 6 & Analysis \\
2 & Size of organization & 7 & Strageic planning \\
3 & Industry & 8 & Selection process \\
4 & Data & 9 & Planning for stratgey execution \\
5 & Level of strastegic planning & & \\
\hline
\end{tabular}

The study considers five different strategies including Critical Success Factors Analysis, Business Systems Planning (Boynton \& Zmud, 1984), Porter's forces model (Porter, 2008), SWOT analysis (Humphrey, 2005), Value chain Analysis (Porter, 1979) and MIN and rank them based on TOPSIS technique.

\section{Discussion and conclusion}

The results of the implementation of TOPSIS has indicated that MIN method is ranked first as the most important factor followed by Business Systems Planning, Porter's forces model, Value chain Analysis, SWOT and CSF for development of strategic planning for information technology in manicipality organization. As we have observed there were various criteria for strategy selection and making appropriate decision required MCDM application.

\section{Acknowledgement}

The authors would like to thank the annonymous referees for constructive comments on earlier version of this paper. 


\section{References}

Aiello, G., Enea, M., Galante, G., \& La Scalia, G. (2009). Clean agent selection approached by fuzzy TOPSIS decision-making method. Fire Technology, 45, 405-418.

Amiri, M. P. (2010). Project selection for oil-fields development by using the AHP and fuzzy TOPSIS methods. Expert Systems with Applications, 37, 6218-6224.

Athanasopoulos, G., Riba, C. R., \& Athanasopoulou, C. (2009). A decision support system for coating selection based on fuzzy logic and multi-criteria decision making. Expert Systems with Applications, 36, 10848-10853.

Awasthi, A., Chauhan, S. S., \& Omrani, H. (2011a). Application of fuzzy TOPSIS in evaluating sustainable transportation systems. Expert Systems with Applications, 38, 12270-12280.

Awasthi, A., Chauhan, S. S., Omrani, H., \& Panahi, A. (2011b). A hybrid approach based on SERVQUAL and fuzzy TOPSIS for evaluating transportation service quality. Computers \& Industrial Engineering, 61, 637-646.

Aydogan, E. K. (2011). Performance measurement model for Turkish aviation firms using the roughAHP and TOPSIS methods under fuzzy environment. Expert Systems with Applications, 38, 3992-3998.

Boynton, A. C., \& Zmud, R. W. (1984). An assessment of critical success factors. Sloan Management Review, 25(4), 17-27.

Chen, S. J., \& Hwang, C. L. (1992). Fuzzy multiple attribute decision making: Methods and applications. Berlin: Springer-Verlag.

Chang, C. H., Lin, J. J., Lin, J. H., \& Chiang, M. C. (2010). Domestic open-end equity mutual fund performance evaluation using extended TOPSIS method with different distance approaches. Expert Systems with Applications, 37, 4642-4649.

Chamodrakas, I., Alexopoulou, N., \& Martakos, D. (2009). Customer evaluation for order acceptance using a novel class of fuzzy methods based on TOPSIS. Expert Systems with Applications, 36, $7409-7415$.

Cheng, D. Y., Chao, K. M., Lo, C. C., \& Tsai, C. F. (2011). A user centric service-oriented modeling approach. World Wide Web, 14, 431-459.

Humphrey, A. (2005). SWOT analysis for management consulting. SRI Alumni Newsletter (SRI International).

Kaplan, R.S. \& Norton, D.P. (1996). The balanced scorecard: translating strategy into action, Harvard Business School Press, Boston, MA.

Kelemenis, A., Ergazakis, K., \& Askounis, D. (2011). Support managers' selection using an extension of fuzzy TOPSIS. Expert Systems with Applications, 38, 2774-2782.

Krohling, R. A., \& Campanharo, V. C. (2011). Fuzzy TOPSIS for group decision making: A case study for accidents with oil spill in the sea. Expert Systems with Applications, 38, 4190-4197.

Porter, M. E. (1979). How competitive forces shape strategy. Harvard Business Review.

Porter, M.E. (2008). The five competitive forces that shape strategy. Harvard business Review, January 2008.

Saaty, T. L. (1992). How to make a decision: the analytic hierarchy process. European Journal of Operational Research, 48, 9-26.

Sun, C. C., \& Lin, G. T. R. (2009). Using fuzzy TOPSIS method for evaluating the competitive advantages of shopping websites. Expert Systems with Applications, 36, 11764-11771.

Yoon, K. P., \& Hwang, C. L. (1995). Multiple attribute decision making. Thousand Oaks, CA: Sage Publication.

Yu, X., Guo, S., Guo, J., \& Huang, X. (2011). Rank B2C e-commerce websites in e-alliance based on AHP and fuzzy TOPSIS. Expert Systems with Applications, 38, 3550-3557. 